\title{
Family-based intervention using face-to- face sessions and social media to improve Malay primary school children's adiposity: a randomized controlled field trial of the Malaysian REDUCE programme
}

Norliza Ahmad', Zalilah Mohd Shariff², Firdaus Mukhtar ${ }^{3}$ and Munn-Sann Lye

\begin{abstract}
Background: Social media may be an effective medium by which parents could be trained to promote healthy eating behaviour and physical activity for their children. This trial evaluates the effectiveness of a family-based intervention using social media in combination with face-to-face sessions - the REDUCE (REorganise Diet, Unnecessary sCreen time and Exercise) programme - on adiposity of Malay children.
\end{abstract}

Methods: Five primary schools in an urban area in Selangor, Malaysia participated in this two-arm randomized controlled field trial. Participants were parents $(n=134)$ and their primary school-going children 8-11 years of age who were either overweight or obese. These parent-child dyads were randomly allocated to intervention and wait-list control groups and were blinded to group assignment. The intervention was a four-week training programme using two face-to-face sessions and two Facebook sessions followed by weekly booster sessions over a three-month period using WhatsApp. The primary outcome was body mass index (BMI) z-score. Height, body weight, waist circumference and percentage of body fat were measured by blinded assessors. Data were collected at baseline (T1), immediately post-training (T2) and at three- (T3) and six-month post training (T4) and were analysed using generalized linear mixed modelling adjusted for covariates to estimate the intervention effects. Subgroup analysis was conducted for overweight and obese children.

Results: Ninety-one percent of parents completed the study, 64 in intervention group and 58 in wait-list group. At the sixth month post-training, BMl z-scores were significantly reduced in the intervention group compared to the wait-list group, for the all children (overweight and obese children) and within the obese subgroup $((F(6,517)=2.817, p=0.010)$ and $(F(6,297)$ $=6.072, p<0.001)$ respectively. For waist circumference percentile and body fat percentage, the intervention group experienced a significant reduction compared to the wait-list group, within the obese subgroup $((F(6,297)=3.998, p=0$. $001)$ and within the overweight subgroup $(F(6,201)=2.526, p=0.022)$.

Conclusions: The four-month REDUCE intervention programme was effective in reducing childhood adiposity. Further research using this approach needs to be conducted including cost-effectiveness studies before implementing it in a child obesity prevention programme.

(Continued on next page)

\footnotetext{
* Correspondence: lyems9@yahoo.com; lyemunn@upm.edu.my

${ }^{1}$ Department of Community Health, Faculty of Medicine and Health Sciences,

Universiti Putra Malaysia, Level 1, Block B (Academic), 43400 UPM, Serdang,

Selangor, Malaysia

Full list of author information is available at the end of the article
}

(c) The Author(s). 2018 Open Access This article is distributed under the terms of the Creative Commons Attribution 4.0 International License (http://creativecommons.org/licenses/by/4.0/), which permits unrestricted use, distribution, and reproduction in any medium, provided you give appropriate credit to the original author(s) and the source, provide a link to the Creative Commons license, and indicate if changes were made. The Creative Commons Public Domain Dedication waiver (http://creativecommons.org/publicdomain/zero/1.0/) applies to the data made available in this article, unless otherwise stated. 
(Continued from previous page)

Trial registration: Australian New Zealand Clinical Trials Registry: ACTRN12617000844347 (7 June 2017 retrospectively registered). National Medical Research Register, Ministry of Health Malaysia: NMRR-14-685-21,874 (July 2014).

Keywords: Paediatric obesity, Social media, Body mass index, Waist circumference, Body fat percentage, Parents intervention, Primary school children

\section{Background}

The prevalence of overweight and obesity among children 5 to 19 years of age was reported to have experienced a tenfold increase worldwide from 11 million in 1975 to 124 million in 2016 [1]. Developing countries are now experiencing such a trend where the relative percentage increase was 59\% between the year 1980 and 2013 compared to $41 \%$ increase in developed countries [2]. In Malaysia - a developing country - the childhood obesity prevalence increased from $3.9 \%$ in 2011 to $11.9 \%$ in 2015 [3, 4]. Because childhood obesity is associated with negative health effects, it warrants serious public health attention to prevent further increase in its prevalence [5].

Some ethnic groups are more affected by obesity and in Malaysia, the Chinese have the highest prevalence of obesity (13.0\%), followed by Indians (12.6\%) and Malays (11.8\%). However, in terms of absolute numbers, Malays form the largest group as they are the ethnic majority in Malaysia and thus are more greatly affected in terms of disease burden. The ethnic composition in Malaysia consists of Malay (52.9\%), Chinese (27.8\%), Indian (13.3\%) and other ethnic groups (6\%) [6]. Healthy lifestyle programmes that are socio-culturally customized may be more effective [7] and thus this intervention programme was tailored to the Malay ethnicity.

Parents can influence the eating behaviour and physical activities of their children; thus intervention programmes that targeted parents as the agent of change had their roots decades ago [8-19]. However, parents often had other commitments that hindered their adherence to face-face intervention programmes [20]. New approaches to educate parents in nutrition and physical activity have emerged - there is an increasing trend in using social media as a mode of communication among young people and adults. As of April 2018, the most common social networking site worldwide was Facebook (2.2 billion), followed by WhatsApp (1.5 billion), You Tube (1.5 billion) and Facebook Messenger (1.3 billion) [21]. About $76.9 \%$ of Malaysians use the Internet, and 97.3\% of them are Facebook users [22]. Systematic reviews of experimental studies on health behaviour intervention concluded that this platform could be effectively used to promote behaviour change [23, 24]. Thus, the use of social networking as a platform to provide health education and impart relevant skills could be feasible and appropriate. Studies have incorporated social media in body weight management [25-28] but using this modality among parents to influence their children is a fairly new concept [23, 29]. Currently overweight and obese children in Malaysia are referred for treatment only if they developed complications. Thus developing a child obesity prevention programme which is parent-friendly and provider-friendly is justified and timely to help curb the increasing prevalence of childhood obesity in Malaysia.

The aim of this study is to evaluate the effectiveness of using social media and face-to-face sessions in a family-based intervention on the primary outcome of body mass index (BMI) z-score and secondary outcomes of waist circumference percentile and percentage total body fat. We also assessed parental factors which include parental knowledge, healthy lifestyles, parental feeding style and parental self-efficacy as well as child factors which include children's eating behaviours, food and beverages consumption (fruit and vegetable, snacks and sugar-sweetened beverages), physical activity and screen time. However, parental factors and child factors are not reported here. We hypothesize that in comparison with the wait-list group, children in the intervention group will have reduced BMI z-score, waist circumference percentile and percentage of total body fat.

\section{Methods}

A detailed elaboration of the methodology of this field trial, has been published elsewhere [30]. However, a summary of the methodology is described here.

\section{Participants and design}

This is a two-armed, parallel, randomized controlled field trial conducted in an urban area in one of the states in Malaysia. An urban area was chosen as the Malaysia National Health and Morbidity Survey (2015) [4] showed that prevalence of childhood obesity was slightly higher in the urban areas than in the rural areas.

All five primary government schools in this area were selected for this study. Before the study was conducted, BMI z-scores of school children in those schools were not available as there was no standardized reporting and referral upon detecting childhood overweight and obesity unless there were complications. Thus the number of children with overweight and obesity were unknown prior 
to the study. Brochures were sent to all the five schools informing parents about the intervention and the study and requesting them for consent to measure weight and height of their school-going children aged 7 to 10 years from August to September 2014. Those children whose parents gave written consent were screened for BMI z-score eligibility in October 2014. Parents who agreed to participate also provided consent on behalf of their children. Parents whose children with BMI z-score of more than 1 standard deviation (SD) were then invited to participate in the study. Parent-child dyads of Malay ethnicity who were computer literate, had access to the internet, were willing to use social media for interaction and children 7 to 10 years of age were recruited. Parents who reported children having co-morbidities, chronic diseases, physical disabilities, learning disabilities, on medication for chronic illness or participated in other research were excluded.

Individual randomisation was used over cluster design as contamination was expected to be low, because parents in the study setting hardly intermingle. In addition, the distribution of schools across intervention and control groups would be unequal because there are five schools and differences in distribution of sociodemographic characteristics and children with weight problems were unknown prior to the study. Each parent-child dyad from all five schools was number coded by the first author (NA) and sent to a research assistant who performed a computer generated randomization list which allocated parents into intervention or wait-list control groups using a simple randomization procedure of an online software (Research Randomiser) [31] with 1:1 allocation. This ensured the concealment of allocation from the rest of the researchers and participants. The list was then provided to the first author to invite the intervention group for the REDUCE intervention program.

Participating parents were informed that the intervention would be done in stages. So, parents would have the understanding that some of them would be participating earlier than others. Eventually all in the wait-listed control group would undergo the same intervention as parents in the intervention group after the final data collection. Parents in the wait-list control group were not informed of the starting of the intervention for the intervention group. The intervention group was informed not to share their social media experience with other parents; in addition they did not know who were in the wait-listed group, hence minimizing contamination. The face-to-face sessions for the intervention group were conducted in the Faculty of Medicine and Health Sciences, UPM without the knowledge of the wait-listed control group.
The researcher (NA) as the implementer of the intervention was not involved in the measurement of the children's weight, height, waist circumference and body fat percentage and data entry.

The sample size was based on a power of $80 \%$ and a level of significance $(\alpha)$ of 0.05 to detect a BMI z-score difference between intervention and wait-list control groups of 0.24 with standard deviation of 0.48 based on a previous study [32]. The dropout rate after randomization was assumed to be $15 \%$ requiring a minimum sample size of 56 parents per arm. The parent-child dyad was based on a 1:1 ratio - one parent to one child. All except two parents had one eligible child who was overweight or obese. For those two parents, the parents were requested to volunteer one other child for the study.

\section{Intervention}

The REDUCE (REorganise Diet, Unnecessary sCreen time and Exercise) intervention programme to impart information and skills was a newly developed programme by the researchers (NA, ZMS and FM) using social cognitive theory (SCT) [33]. The programme trained the parents on children's nutrition, physical activity, behaviour modification techniques and parenting skills to improve their children's health behaviours. The SCT posits behaviour as a reciprocal interaction between the person and environmental factors. The person is the child and the environment is the home environment and the parental factors that are conducive to the children's behaviour change. The child's ultimate daily targeted behaviours included no consumption of sugar-sweetened beverages (SSB) and unhealthy snacks, intake at least five servings of fruit and vegetables (two servings of fruit and three servings of vegetables), a minimum of $30 \mathrm{~min}$ of moderate to vigorous physical activity and a maximum of $120 \mathrm{~min}$ of screen time (watching television and playing video games). However, parents and children were empowered to choose which of the five targets to start working towards, first starting with the more manageable to achieve targets and to make small changes, one at a time. The elements of behaviour modification skills in the SCT include self-monitoring, goal setting, self-efficacy, problem solving, relapse prevention, and stimulus control. Parents were encouraged to acquire authoritative parenting skills, practise healthy behaviours and improve self-efficacy of child's healthy behaviours. The four-month REDUCE intervention programme consisted of 4 weeks of weekly training and 3 months of weekly booster.

The four-week training phase of the REDUCE intervention module was comprised of 8 units; 2 units were delivered through half-day face-to-face sessions (session one) followed by 2 units delivered weekly via Facebook 
for 2 weeks, and finally the last 2 units delivered via half-day face-to-face sessions (session two). The face-to-face sessions were conducted at the Faculty of Medicine and Health Sciences, University Putra Malaysia. All 4 units delivered in the face-to-face sessions were subsequently uploaded on the Facebook after each session. The training contents are summarized in Table 1. All the training sessions were delivered by the first author (NA) who is a public health physician except for the exercise tips in unit 8 which was conducted by a sports medicine specialist. All units were delivered to parents only, except for units 7 and 8 which were delivered to parents and children.

The booster phase of the REDUCE intervention programme were weekly one-hour sessions using parents' dedicated WhatsApp group that lasted for 12 weeks. The aims of the booster phase were to strengthen parents' knowledge and skills in promoting the targeted behaviours of the REDUCE programme. In this phase the first author (NA) posted on WhatsApp key information and skills provided in the training phase but in the form of a poster, responded to any queries by parents and provided feedback on the adiposity progress of the children based on the measurements taken. Parents were encouraged to enquire and discuss with the researcher (NA) and to interact with other parents in the intervention group in order to promote programme adherence and maintain motivation using this platform. The total contact time between researcher and participants was 22 h. Programme adherence was assessed by percentage of parents who attended the face-to-face sessions, and accessed the information in the Facebook as well as messages in the WhatsApp. Parents' responses were also compared between Facebook and What sApp.

The wait-list control group received the intervention after the completion of the final 6-month follow-up. To minimize attrition among intervention and wait-list control groups, small incentives (mainly stationeries) were given to the children each time they participated in the physical measurements and returned the parent-administered questionnaires.

\section{Parents' involvement}

In the pilot testing of the REDUCE intervention module, Malay parents of obese and overweight primary school children were involved in providing feedback on the module's duration, mode of delivery and the performance feedback of the children's progress over an eight-week training programme delivered only via Facebook.

In the randomized controlled trial, parents in the intervention group were informed of their children's progress via WhatsApp after each data collection immediately post-training, at 3 months and 6 months post-training while parents in the wait-listed group received feedback at similar times after the study ended. Feedback was obtained from parents in the intervention group regarding the burden or otherwise of the intervention.

\section{Measures}

The primary outcome was BMI z-score while waist circumference percentile and percentage of total body fat were secondary outcomes. BMI z-score which was determined using the WHO Anthroplus software [34] with weight in $\mathrm{kg}$, height in $\mathrm{cm}$, gender and age. Height was measured using a portable Seca stadiometer to the nearest $0.1 \mathrm{~cm}$ with bare feet. Weight was measured using the Omron Karada Scan (model HBF 212) to the nearest $0.1 \mathrm{~kg}$ with light clothing on and empty pockets.

Waist circumference was measured using Seca non-extensible tape meter at the approximate midpoint between the lower margin of the last palpable rib and the top of the iliac crest at the end of normal expiration [35]. The waist circumference was then converted to waist circumference percentile for Malaysian children by reading off the table on percentile values of $\mathrm{WC}(\mathrm{cm})$ by age and gender [36]. Percentage of body fat was measured after weight measurement using the same scale to

Table 1 Contents of REDUCE intervention module

\begin{tabular}{|c|c|c|c|c|}
\hline Week & Unit & Approach & Themes & Behaviour modification techniques \\
\hline \multirow[t]{2}{*}{1} & 1 & \multirow[t]{2}{*}{$\begin{array}{l}\text { Face-to-face } \\
\text { session one }\end{array}$} & $\begin{array}{l}\text { Introduction, obesity overview, parenting skills and } \\
\text { role modelling }\end{array}$ & \multirow[t]{2}{*}{$\begin{array}{l}\text { Goal setting, self-monitoring, self-efficacy, problem solving } \\
\text { and stimulus control }\end{array}$} \\
\hline & 2 & & Sugar-sweetened beverages & \\
\hline \multirow[t]{2}{*}{2} & 3 & \multirow[t]{4}{*}{ Facebook } & Fruits and vegetables & \multirow{4}{*}{$\begin{array}{l}\text { Goal setting, self-monitoring, self-efficacy, problem solving } \\
\text { and stimulus control }\end{array}$} \\
\hline & 4 & & Unhealthy snacks & \\
\hline \multirow[t]{2}{*}{3} & 5 & & Physical activity & \\
\hline & 6 & & Screen time & \\
\hline \multirow[t]{2}{*}{4} & 7 & \multirow{2}{*}{$\begin{array}{l}\text { Face-to-face } \\
\text { session two }\end{array}$} & Risky situations and review of performance & \multirow[t]{2}{*}{ Relapse prevention } \\
\hline & 8 & & $\begin{array}{l}\text { Further roles and actions, exercise tips and success } \\
\text { stories }\end{array}$ & \\
\hline
\end{tabular}


the nearest $0.1 \%$. All physical measurements were performed by trained research assistants who were blinded regarding the allocation status of these children. The implementer of the intervention (NA) was not involved in any of these measurements. Each type of measurement was assigned to a designated trained research assistant to minimize inter-rater measurement bias. For example, a research assistant who did waist circumference only measured waist circumference. Assessments were completed at baseline, immediate post-training, 3 months and 6 months post-training.

Sociodemographic information was collected at baseline comprising of child's data on birth date, gender, number of siblings, order in the family and parents' data on marital status, education level and income. Parents' self-report on weight and height were also collected at baseline to determine parents' BMI.

\section{Statistical analysis}

Data were analysed using SPSS version 22.0. Tests for normality were done using skewness, kurtosis, and graphs (histogram with normal distribution curve, whisker boxplot, and Q-Q and P-P plots) before further analyses were conducted. Non-normally distributed data were $\log$ transformed first before further analysis. Differences between intervention and wait-list control at baseline were tested using independent $t$-test (continuous variables) or chi-square test or Fischer's exact test (categorical variables) to examine the homogeneity between groups. All follow-up outcomes were analysed with intention-to-treat analysis.

Changes in BMI z-score, waist circumference percentile and percentage of total body fat were compared between intervention and wait-list control groups using independent $t$-test for continuous variables. The effectiveness of the intervention was evaluated using generalized linear mixed modelling adjusted for baseline covariates. Covariates included were variables that could affect body weight - child's age, child's gender, parents' BMI, parents' education, family income, and child's adiposity baseline measurements (BMI z-score, waist circumference percentile and percentage body fat). Subgroup analysis was conducted for overweight and obese children. The level of significance was set at $\alpha=$ 0.05 , and the null hypothesis rejected when $p \leq 0.05$. The CONSORT checklist of this study is in the Additional file 1.

\section{Results}

One hundred and twenty-two parents completed this study giving an overall response rate of $91 \%$ among parents (64 parents in the intervention group and 58 parents in the wait-list control group were available for analysis). Parents who did not return the questionnaire after defaulting three follow-up sessions were considered dropouts. There was no significant difference between parents who remained in the study and parents who dropped out in terms of sociodemographic characteristics, parental BMI and the anthropometric measurements of their children. There was complete data for anthropometry and body fat percentage of all the children at all the four time points. The CONSORT flow diagram of parent-child participation is shown in Fig. 1.

Table 2 shows the baseline measurements of the respondents. There was no significant difference between the intervention and control groups at baseline. There was no unintended effect reported by the participants in the intervention and wait-list groups.

\section{Programme adherence}

96.9\% of parents participated in WhatsApp and $81.3 \%$ in Facebook respectively, compared to $68.8 \%$ for session one and $42.2 \%$ for session two of the face-to-face sessions. Since all the material used in the face-to-face sessions was uploaded on the Facebook after each session, the contents of the face-to-face sessions thus were available for all parents in the intervention group. Parents' adherence in WhatsApp was by counting the number of times they accessed the messages. Table 3 shows parents' participation and characteristics in WhatsApp and Facebook. One quarter of the parents' responses (82/356) expressed support for the programme. Examples of texted support included: expressing thanks for having the programme, welcoming other group members, texting phrases such as 'to make healthy and happy family' and congratulating group members who managed to reduce their children's BMI. One fifth of the responses (77/356) shared the parents' or their child's progress. For example, they reported on their children's improvement in reducing sugar-sweetened beverages, their ways of doing so and their children's activities. Another one fifth of the responses (75/356) gave simple replies. Examples included thank you, thumbs up and a smiley emoji.

\section{Impact on children's adiposity}

Changes in children's adiposity for the intervention and wait-list control groups over the course of the study are shown in Table 4. There were increases in mean differences between intervention and wait-list control groups observed in BMI z-score and waist circumference percentile over the study period and these differences were significant at the end of 6 months $(p=0.045$ and $p=$ 0.021 respectively).

Table 5 shows the changes in adiposity between baseline and six-month follow-up for the whole sample, overweight and obese subgroups. The mean decrease in BMI z-score was $0.10 \pm 0.26$ for whole sample and 0.11 \pm 0.14 for obese subgroup in the intervention group. The wait-list control group had higher increment in 


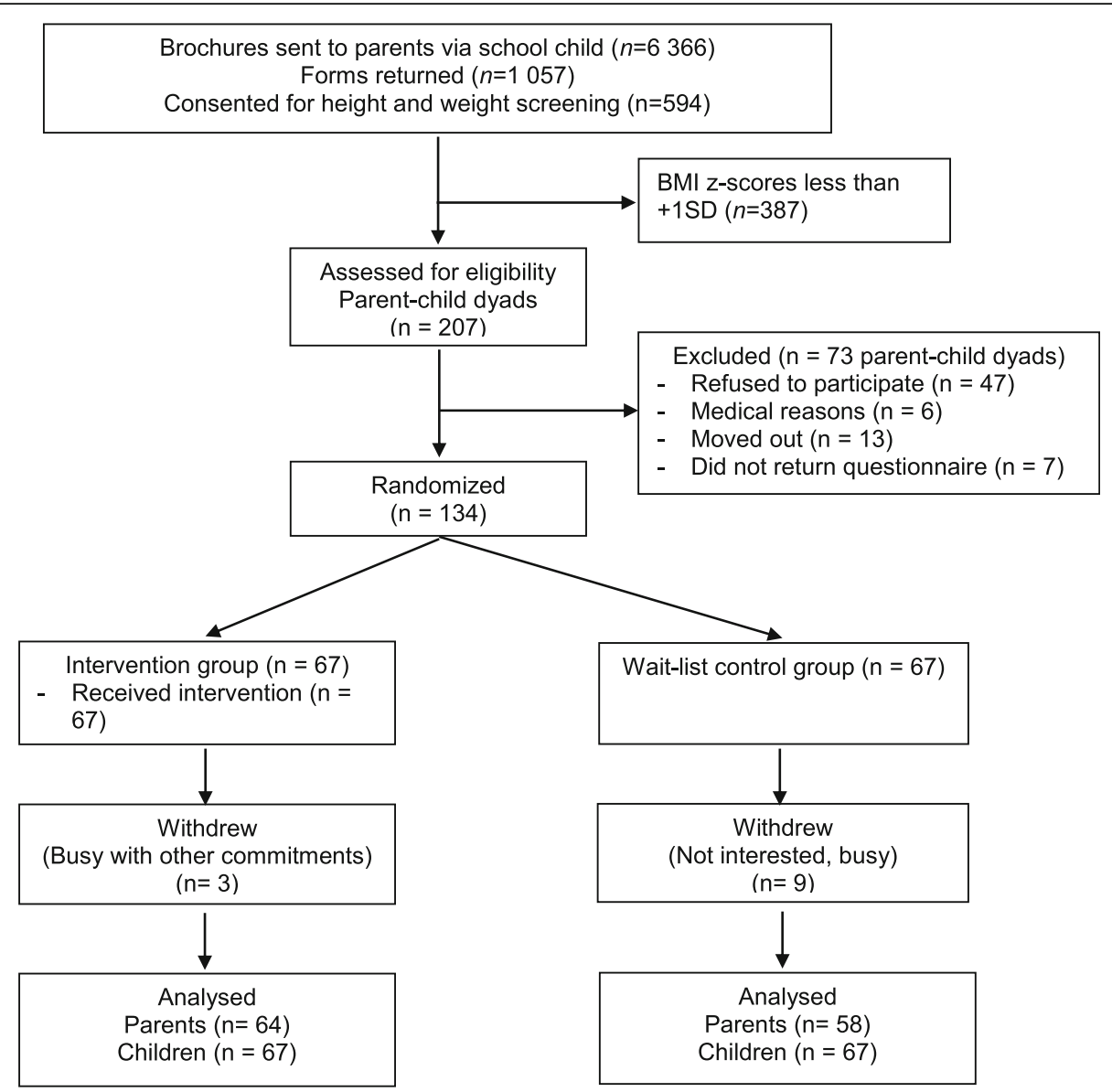

Fig. 1 CONSORT flow diagram of parent-child's participation throughout study period

Table 2 Baseline characteristics of the sample

\begin{tabular}{|c|c|c|c|c|c|}
\hline \multirow[t]{2}{*}{ Characteristics } & \multicolumn{2}{|c|}{ Intervention $(n=67)$} & \multicolumn{2}{|c|}{ Wait-list control $(n=67)$} & \multirow{2}{*}{$\begin{array}{l}P \\
\text { value }\end{array}$} \\
\hline & $\mathrm{n}(\%)$ & Mean \pm SD & $\mathrm{n}(\%)$ & Mean \pm SD & \\
\hline \multicolumn{6}{|l|}{ Parent } \\
\hline Age (years) & & $39.8(3.6)$ & & $41.3(5.7)$ & 0.079 \\
\hline Gender - female & $39(58.2)$ & & $37(55.2)$ & & 0.862 \\
\hline BMI $\left(\mathrm{kg} / \mathrm{m}^{2}\right)$ & & $27.4(4.41)$ & & $27.8(4.27)$ & 0.622 \\
\hline \multicolumn{6}{|l|}{ Child } \\
\hline Age (years) & & $9.6(1.2)$ & & $9.6(1.2)$ & 0.826 \\
\hline Gender - female & $40(59.7)$ & & $38(56.7)$ & & 0.861 \\
\hline Height (cm) & & $136.1(8.6)$ & & $135.6(9.2)$ & 0.753 \\
\hline Weight (kg) & & $47.0(10.5)$ & & $48.2(12.0)$ & 0.537 \\
\hline BMl & & $25.2(3.5)$ & & $25.7(3.9)$ & 0.272 \\
\hline BMl z-score & & $2.0(0.4)$ & & $2.1(0.4)$ & 0.381 \\
\hline BMI z-score category & & & & & 0.861 \\
\hline Overweight & $28(41.8)$ & & $27(40.3)$ & & \\
\hline Obese & $39(58.2)$ & & $40(59.7)$ & & \\
\hline Waist circumference (cm) & & $77.7(8.8)$ & & $78.8(9.1)$ & 0.465 \\
\hline Waist circumference percentile & & $90.2(8.0)$ & & $91.3(7.0)$ & 0.410 \\
\hline Total body fat & & $37.9(4.2)$ & & $37.6(4.1)$ & 0.740 \\
\hline
\end{tabular}


Table 3 Parents' participation and characteristics in WhatsApp and Facebook

\begin{tabular}{|c|c|c|}
\hline Characteristics & $\begin{array}{l}\text { WhatsApp } \\
\mathrm{n}(\%)\end{array}$ & $\begin{array}{l}\text { Facebook } \\
\mathrm{n}(\%)\end{array}$ \\
\hline Initial number of parents at start of study, n (\%) & $64(96)$ & $64(96)$ \\
\hline Number of parents who left group, $n(\%)$ & $3(4)$ & $3(4)$ \\
\hline Total responses by parents & 356 & 135 \\
\hline Total posts and responses by researcher & 179 & 34 \\
\hline \multicolumn{3}{|l|}{ Responses by parents: } \\
\hline Request clarification on the post & 9 & - \\
\hline Support programme & 82 & 45 \\
\hline Sharing of their problems or progress or child's progress & 77 & 8 \\
\hline Request regarding child's progress & 20 & 3 \\
\hline Sharing information about food and physical activity & 24 & 2 \\
\hline Simple replies (e.g. thank you, thumbs up, smiley emoji) & 75 & 73 \\
\hline Suggestions to improve children's obesity issue at school level and national level & 6 & - \\
\hline Enquiry about other health issues & 4 & - \\
\hline Others & 59 & 4 \\
\hline \multicolumn{3}{|l|}{ Responses per parent: } \\
\hline $1-5$ & 35 & 36 \\
\hline $6-10$ & 18 & 14 \\
\hline$\geq 11$ & 11 & 14 \\
\hline
\end{tabular}

Table 4 Changes in child's adiposity between intervention and wait-list groups from baseline to 6-month post-training

\begin{tabular}{|c|c|c|c|c|}
\hline \multirow[t]{2}{*}{ Variables } & \multicolumn{4}{|l|}{$\begin{array}{l}\text { Data }(N=134) \\
\text { Means } \pm S D\end{array}$} \\
\hline & Baseline & Immediately post-training & 3-month post-training & 6-month post-training \\
\hline \multicolumn{5}{|l|}{ BMl z-scores } \\
\hline Intervention group ( $n=67)$ & $2.05 \pm 0.40$ & $2.03 \pm 0.38$ & $1.99 \pm 0.41$ & $1.95 \pm 0.45$ \\
\hline Wait-list group $(n=67)$ & $2.11 \pm 0.39$ & $2.10 \pm 0.36$ & $2.11 \pm 0.35$ & $2.09 \pm 0.35$ \\
\hline t-test ( $p$-value) & $-0.879(p=0.381)$ & $-1.158(p=0.249)$ & $-1.730(p=0.086)$ & $-2.025(p=0.045)^{a}$ \\
\hline Mean difference & -0.06 & -0.07 & -0.11 & -0.14 \\
\hline 95\% Cl for mean difference & -0.194 to 0.075 & -0.200 to 0.052 & -0.244 to 0.016 & -0.278 to -0.003 \\
\hline \multicolumn{5}{|l|}{ Waist circumference percentile } \\
\hline Intervention group $(n=67)$ & $90.21 \pm 7.98$ & $91.09 \pm 7.71$ & $90.06 \pm 9.56$ & $89.37 \pm 9.26$ \\
\hline Wait-list group $(n=67)$ & $91.28 \pm 7.04$ & $93.82 \pm 4.31$ & $92.25 \pm 6.11$ & $92.55 \pm 6.20$ \\
\hline t-test ( $p$-value) & $-0.826(p=0.410)$ & $-2.532(p=0.013)^{a}$ & $-1.583(p=0.116)$ & $-2.335(p=0.021)^{a}$ \\
\hline Mean difference & -1.07 & -2.73 & -2.19 & -3.18 \\
\hline 95\% Cl for mean difference & -3.647 to 1.498 & -4.871 to -0.592 & -4.940 to 0.552 & -5.876 to -0.482 \\
\hline \multicolumn{5}{|l|}{ Percentage of body fat } \\
\hline Intervention group ( $n=67)$ & $37.87 \pm 4.20$ & $37.68 \pm 4.14$ & $36.66 \pm 4.75$ & $36.75 \pm 4.75$ \\
\hline Wait-list group $(n=67)$ & $37.63 \pm 4.09$ & $37.23 \pm 4.50$ & $37.65 \pm 4.25$ & $37.25 \pm 4.46$ \\
\hline t-test (p-value) & $0.333(p=0.740)$ & $0.603(p=0.548)$ & $-1.263(p=0.209)$ & $-0.630(p=0.530)$ \\
\hline Mean difference & 0.24 & 0.45 & -0.98 & -0.50 \\
\hline 95\% Cl for mean difference & -1.178 to 1.654 & -1.027 to 1.927 & -2.524 to 0.557 & -2.077 to -1.074 \\
\hline
\end{tabular}


Table 5 Comparison of changes in adiposity within groups between baseline and six-month follow-up

\begin{tabular}{|c|c|c|c|}
\hline & Mean difference \pm SD baseline vs 6-month ${ }^{c}$ & $\mathrm{t}$ & $p$-value $^{a}$ \\
\hline \multicolumn{4}{|l|}{ BMI z-score } \\
\hline \multicolumn{4}{|l|}{ Whole sample } \\
\hline Intervention group ( $n=67)$ & $0.100 \pm 0.257$ & 3.190 & $0.002^{b}$ \\
\hline Wait-list group $(n=67)$ & $0.019 \pm 0.172$ & 0.907 & 0.368 \\
\hline \multicolumn{4}{|l|}{ Overweight children } \\
\hline Intervention group $(n=28)$ & $0.087 \pm 0.367$ & 1.257 & 0.220 \\
\hline Wait-list group $(n=27)$ & $-0.067 \pm 0.185$ & -1.887 & 0.070 \\
\hline \multicolumn{4}{|l|}{ Obese children } \\
\hline Intervention group $(n=39)$ & $0.109 \pm 0.136$ & 5.022 & $<0.001^{\mathrm{b}}$ \\
\hline Wait-list group $(n=40)$ & $0.077 \pm 0.138$ & 3.545 & $0.001^{\mathrm{b}}$ \\
\hline \multicolumn{4}{|l|}{ Waist circumference percentile } \\
\hline \multicolumn{4}{|l|}{ Whole sample } \\
\hline Intervention group $(n=67)$ & $1.373 \pm 11.079$ & 1.014 & 0.314 \\
\hline Wait-list group $(n=67)$ & $-1.343 \pm 9.019$ & -1.219 & 0.227 \\
\hline \multicolumn{4}{|l|}{ Overweight children } \\
\hline Intervention group $(n=28)$ & $5.357 \pm 14.095$ & 2.011 & 0.054 \\
\hline Wait-list group $(n=27)$ & $0.963 \pm 9.382$ & 0.533 & 0.598 \\
\hline \multicolumn{4}{|l|}{ Obese children } \\
\hline Intervention group $(n=39)$ & $-1.487 \pm 7.207$ & -1.289 & 0.205 \\
\hline Wait-list group $(n=40)$ & $-2.900 \pm 8.533$ & -2.149 & $0.038^{b}$ \\
\hline \multicolumn{4}{|l|}{ Percentage of total body fat } \\
\hline \multicolumn{4}{|l|}{ Whole sample } \\
\hline Intervention group ( $n=67)$ & $0.912 \pm 6.053$ & 1.234 & 0.222 \\
\hline Wait-list group $(n=67)$ & $0.655 \pm 6.694$ & 0.801 & 0.426 \\
\hline \multicolumn{4}{|l|}{ Overweight children } \\
\hline Intervention group $(n=28)$ & $2.451 \pm 6.736$ & 1.926 & 0.065 \\
\hline Wait-list group $(n=27)$ & $1.963 \pm 5.961$ & 1.711 & 0.099 \\
\hline \multicolumn{4}{|l|}{ Obese children } \\
\hline Intervention group $(n=39)$ & $-0.193 \pm 5.330$ & -0.226 & 0.822 \\
\hline Wait-list group $(n=40)$ & $-0.227 \pm 7.083$ & -0.203 & 0.840 \\
\hline
\end{tabular}

asing paired t-test; SD: standard deviation

${ }^{\mathrm{b}}$ Significant at $p \leq 0.05$.

'This difference is baseline minus 6 month, with minus value depicting a higher measurement at 6-month post-training compared to baseline

mean waist circumference percentile at six-month follow-up (2.9 $\mathrm{cm} \pm 8.5)$ compared to intervention group $(1.5 \mathrm{~cm} \pm 7.2)$. There was a higher reduction in within-group change for percentage of total body fat at six-month follow-up for overweight children in the intervention group $(2.5 \% \pm 6.7)$ compared to the wait-list group. However, this change was not significant ( $p=$ 0.065).

Results from the mixed model analysis (Table 6) showed that at the end of 6 months, significantly higher proportion of children in the intervention group than in the wait-list group had reduced BMI z-score for all (F(6, $517)=2.817, p=0.010)$. Among obese children $(\mathrm{F}(6$,
$297)=6.072, p=<0.001)$, more children in the intervention group had reduced their waist circumference percentile $(\mathrm{F}(6,297)=3.998, p=0.001)$ compared to the control group, while more overweight children in the intervention group had reduced their body fat percentage compared to the control group $(F(6,201)=2.526$, $p=0.022)$. Figure 2 shows changes in BMI z-scores, waist circumference percentile and body fat percentage from the mixed model analysis, between baseline and at 6 months $(\mathrm{p}=0.01, \mathrm{p}=0.001$ and $\mathrm{p}=0.022$ respectively).

We received positive feedback from parents regarding the use of social media. Parents felt social media was convenient to use and facilitated direct communication 
Table 6 Comparison of anthropometric measurements and body fat percentage between study groups, controlling for covariates

\begin{tabular}{|c|c|c|c|c|c|}
\hline Variable & Parameter & $\mathrm{F}$ & $\mathrm{df1}$ & $\mathrm{df2}$ & $p$-value ${ }^{a}$ \\
\hline \multicolumn{6}{|l|}{ BMI z-scores } \\
\hline Whole sample & Group & 7.050 & 1 & 517 & $0.008^{b}$ \\
\hline$(n=134)$ & Group x Time & 2.817 & 6 & 517 & $0.010^{b}$ \\
\hline Overweight subgroup & Group & 9.341 & 1 & 201 & $0.003^{b}$ \\
\hline$(n=55)$ & Group x Time & 1.218 & 6 & 201 & 0.299 \\
\hline Obese subgroup & Group & 0.033 & 1 & 297 & 0.855 \\
\hline$(n=79)$ & Group x Time & 6.072 & 6 & 297 & $<0.001^{b}$ \\
\hline \multicolumn{6}{|c|}{ Waist circumference percentile } \\
\hline Whole sample & Group & 13.935 & 1 & 517 & $<0.001^{\mathrm{b}}$ \\
\hline$(n=134)$ & Group x Time & 1.410 & 6 & 517 & 0.209 \\
\hline Overweight subgroup & Group & 30.245 & 1 & 201 & $<0.001^{\mathrm{b}}$ \\
\hline$(n=55)$ & Group x Time & 1.683 & 6 & 201 & 0.127 \\
\hline Obese subgroup & Group & 0.084 & 1 & 297 & 0.772 \\
\hline$(n=79)$ & Group x Time & 3.998 & 6 & 297 & $0.001^{b}$ \\
\hline \multicolumn{6}{|l|}{ Body fat percentage } \\
\hline Whole sample- & Group & 1.454 & 1 & 517 & 0.228 \\
\hline$(n=134)$ & Group $\times$ Time & 0.802 & 6 & 517 & 0.569 \\
\hline Overweight subgroup & Group & 0.575 & 1 & 201 & 0.449 \\
\hline$(n=55)$ & Group x Time & 2.526 & 6 & 201 & $0.022^{b}$ \\
\hline Obese subgroup & Group & 0.093 & 1 & 297 & 0.760 \\
\hline$(n=79)$ & Group x Time & 0.628 & 6 & 297 & 0.708 \\
\hline
\end{tabular}

asing generalized linear mixed model adjusted for child's age, child's gender, parents' body mass index, mother's education, father's education, family income, and child's baseline data (BMI z-score, waist circumference percentile and body fat percentage respectively)

${ }^{b}$ Significant at $p \leq 0.05$

with the researcher who provided the needed support. It also made possible discussion to solve problems that parents may face regarding the study, and enabled performance feedback to the parents.

\section{Discussion}

In this randomized controlled field trial, our results suggest that the use of social media and face-to-face sessions in the family-based, theory-driven intervention for management of childhood obesity can decrease children's adiposity (BMI z-score, waist circumference percentile and percentage of body fat). No adverse events or unintended adverse consequences of the intervention were reported by the participants.

These results showed almost similar magnitude of decrease in BMI z-score found in Cochrane meta-analysis among 37 studies for children aged 6-12 years with mean effect of -0.15 (95\% CI: -0.23 to -0.08 ) [37]. This difference is expected to have clinical benefits as a study by Kolsgaard et al. (2011) showed that even a modest reduction in BMI z-score $(\geq 0.00-<0.1)$ was associated with significant improvement in several cardiovascular risk factors i.e. improved insulin and insulin resistance, total cholesterol, LDL cholesterol and total/HDL cholesterol ratio [38].

A recent systematic review and meta-analysis of eight studies examining the effectiveness of family-based eHealth intervention among overweight and obese children and adolescents found that the difference in BMI or BMI z-score between the intervention and control groups at post-intervention were not statistically significant [39]. The REDUCE intervention also produced a greater reduction in BMI $\mathrm{z}$-scores than some of the face-to-face only interventions for parents of overweight and obese children [40-44] that measured similar outcomes. We postulate that a combination of social media and face-to-face intervention may have produced more favourable results compared with standalone intervention of either internet/social media or face-to-face intervention. The results of the REDUCE intervention compare favourably with a more intensive intervention [32] that involved 18 two-hour face-to-face sessions delivered over 9 weeks. There are, however, some face-to-face interventions that have produced larger group differences than the REDUCE intervention $[12,45]$. Their interventions however, involved more sessions than the REDUCE intervention.

Subgroup analysis showed that in the intervention group, obese children had significantly lesser increment at the end of the 6-month post-training in waist circumference percentile whereas overweight children had significantly reduced percentage of total body fat compared to the wait-list group. The result of our study was comparable to those of a face-to-face intervention study by Sacher et al. [32]. Their intervention resulted in a$4.1 \mathrm{~cm}$ significant difference in waist circumference between intervention $(77.7 \pm 7.2 \mathrm{~cm})$ and control groups $(82.0 \pm 8.6 \mathrm{~cm})$ over a six-month period. Our study showed a $-4.1 \mathrm{~cm}$ difference in waist circumference between intervention $(71.49 \pm 6.04 \mathrm{~cm})$ and wait-list $(75.63$ $\pm 6.49 \mathrm{~cm}$ ) groups for overweight children at six-month follow-up even though it was not significant, most likely due to insufficient power. The study by Reinehr et al. (2010) among overweight children also found a significant difference between the waist circumference of the intervention and control groups [46]. However, other conventional family-based behavioural treatment of childhood obesity found no difference in waist circumference between the intervention and control groups $[41,43]$.

The REDUCE intervention had a greater impact on percentage body fat than another Internet-based family intervention [47] and a conventional family intervention [32] both of which found no difference between intervention and wait-list groups after the same period of 


\section{a}

whole sample

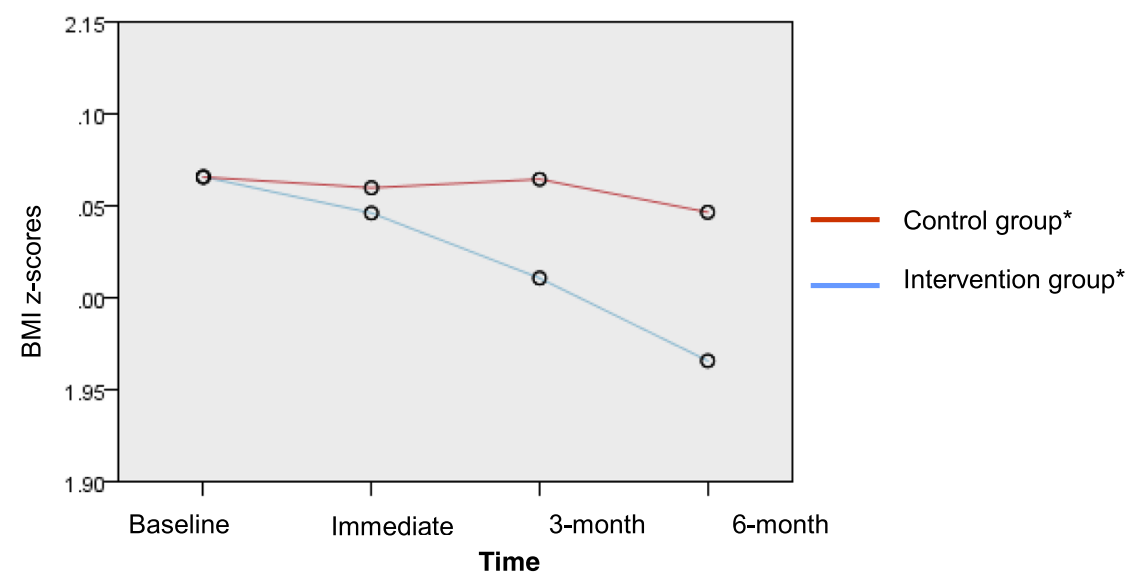

${ }^{*} p=0.01$

b

obese subgroup

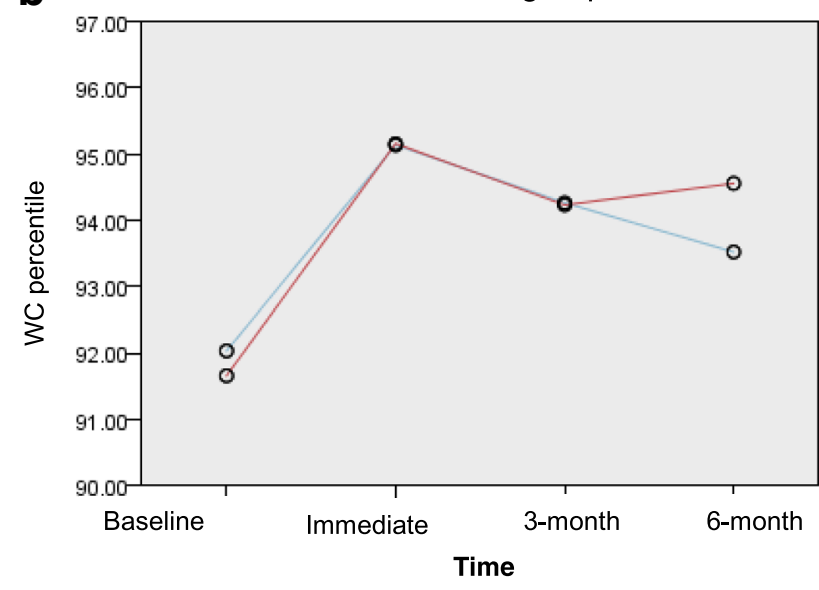

Control group*

Intervention group*

${ }^{*} p=0.001$

C

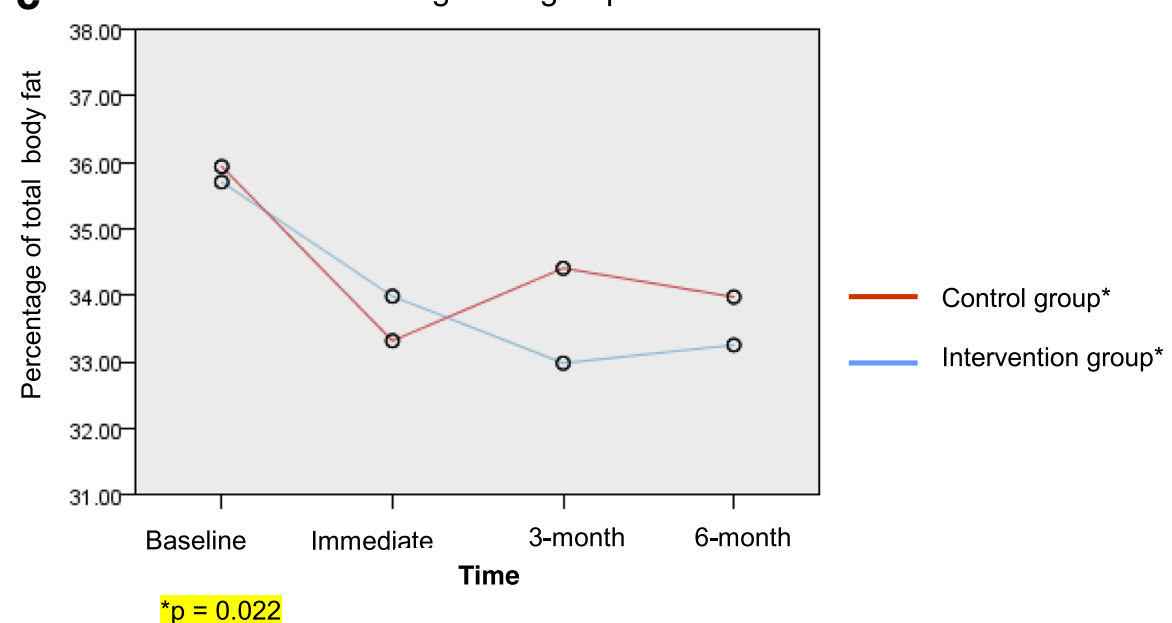

Fig. 2 Changes in BMI z-scores, waist circumference percentile and body fat percentage from the mixed model analysis, between baseline and at 6 months 
follow-up. However, they did not perform subgroup analysis based on obesity status (overweight or obese). The children in our study had high values of percentage body fat with a mean value of more than 35\%. Yamashita et al. (2012) had suggested the cut-off point for cardiovascular risk for Asian adults to be 20.3\% [48]. No cut-off point as yet has been developed for children but the values found in the current study are much higher compared with the adult values, putting these children potentially at elevated cardiovascular risk later in life.

Our study showed a high response rate in the intervention group, with higher rates of parents' participation in the WhatsApp and Facebook sessions compared to face-to-face sessions, indicating that the social media approach is better received than the face-to-face sessions. This is possibly due to the rigid nature of the face-to-face sessions where parents had to attend the sessions within the allocated time, making these sessions least attended. However, omitting the face-to-face approach could possibly have affected the results of this study. In comparing parents' participation in the two types of social media i.e. Facebook and WhatsApp, results showed a greater participation in WhatsApp. We postulate that this was due to the longer duration of contact with parents (3 months) in WhatsApp compared to Facebook (1 month). Facebook has been reported to be the most commonly used social medium in delivering health interventions compared to other social media [23]. However, the use of WhatsApp in health settings has not been widely established as yet. A study by Cheung et al. evaluated the effectiveness of using WhatsApp or Facebook to prevent smoking relapse in recent quitters and found that respondents were more likely to participate using WhatsApp (76\%) than Facebook (42\%) [49]. WhatsApp may be gaining greater acceptance than Facebook because its features are more convenient and easier to use without requiring logging in, or a username and password [49-51]. Apart from notifying smartphone users about incoming messages, WhatsApp allows them to make quick and simple responses and the messages were encrypted $[50,51]$. During the training phase of this intervention, Facebook was used because at that time, WhatsApp did not support the uploading of documents. Even though this function was introduced when the booster phase began, nevertheless, downloading inordinately large documents via WhatsApp caused mobile phones to cease to respond.

The intervention incorporated setting realistic and achievable goals for the children. However, there are several limitations to this study. Generalizability is limited due to the sample being among urban, Malay and educated parents. The respondents could possibly have been highly motivated parents. Parents' BMI was self-reported with the possibility of recall bias being introduced. The poor attendance in face-to-face sessions could have affected the effectiveness of the intervention. To minimize this effect, the respective materials of the module were uploaded to Facebook, and the parents' adherence in Facebook was assessed by the number and percentage who accessed this module. However, we were not able to determine the association between adherence and outcomes as we did not measure individual adherence scores. Another limitation is that the effect of other influences outside the home environment was not controlled for. Lastly, this study was retrospectively registered. However, there was no element of selective reporting for this study, with the original protocol uploaded in its entirety. Future research should be conducted to have a longer follow-up with a cost-effectiveness study before implementing this programme in child obesity prevention programme.

\section{Conclusions}

The REDUCE intervention programme shows that it is possible, in an urban Malay community, to reduce childhood adiposity in primary school children by using a combined face-to-face approach and social media in educating parents on child nutrition, physical activity, behaviour modification techniques and parenting skills. This study thus provides evidence of the potential usefulness of using face-to-face interaction and social media for a family-based intervention in urban community settings to help curb the epidemic of childhood obesity. However, a longer duration of study is needed to ascertain the sustainability of the intervention. A cost-effectiveness study is recommended before incorporating this intervention in a child obesity prevention programme.

\section{Additional files}

Additional file 1: 2017 CONSORT checklist of information to include when reporting a randomized trial assessing nonpharmacologic treatments (NPTs). (DOCX $51 \mathrm{~kb})$

\section{Abbreviations}

BM: Body mass index; REDUCE: Reorganise diet, unnecessary screen time and exercise; SCT: Social cognitive theory

\section{Acknowledgements}

The authors thank the Ministry of Education, school principals and teachers as well as parents and students who participated in this study.

\section{Funding}

The research was funded by Universiti Putra Malaysia, grant number GP-IPS/ 2013/9398400. The funding agency did not influence the planning and execution of this study.

\section{Availability of data and materials}

The datasets used and analysed during the current study are available from the corresponding author on reasonable request.

\section{Authors' contributions}

NA was the principle researcher and was responsible for the data collection and performing the data analysis. NA, LMS, ZMS and FM contributed to the 
study design and supervision. LMS advised and supervised the analyses and edited the manuscript. All authors were involved in writing the paper and authorized final approval of the submitted and published versions.

\section{Ethics approval and consent to participate}

This study was approved by the Medical Research Ethics Committee for Human Research, Universiti Putra Malaysia (Ref: UPM/TNCPI/RMC/1.4.18.1 (JKEUPM)/F2). Approvals were also received from Ministry of Education, State Education Office, District Education Office and Headmaster of each school. All parents were given the respondents' information and consent forms that clearly explained the study prior to recruitment. Parents also provided consent on behalf of their children to participate in this study.

\section{Consent for publication}

Not applicable.

\section{Competing interests}

The authors declare that they have no competing interests.

\section{Publisher's Note}

Springer Nature remains neutral with regard to jurisdictional claims in published maps and institutional affiliations.

\section{Author details}

'Department of Community Health, Faculty of Medicine and Health Sciences, Universiti Putra Malaysia, Level 1, Block B (Academic), 43400 UPM, Serdang, Selangor, Malaysia. ${ }^{2}$ Department of Nutrition, Faculty of Medicine and Health Sciences, Universiti Putra Malaysia, Serdang, Selangor, Malaysia. ${ }^{3}$ Department of Psychiatry, Faculty of Medicine and Health Sciences, Universiti Putra Malaysia, Serdang, Selangor, Malaysia.

\section{Received: 26 March 2018 Accepted: 10 July 2018}

\section{Published online: 02 August 2018}

\section{References}

1. World Heath Organization. New global estimates of child and adolescent obesity released on World Obesity Day. 2017. Available from: http://www.who.int/end-childhood-obesity/news/new-estimate-childadolescent-obesity/en/. Accessed 17 Oct 2017.

2. Ng M, Fleming T, Robinson M, Thomson B, Graetz N, Margono C, et al. Global, regional, and national prevalence of overweight and obesity in children and adults during 1980-2013: a systematic analysis for the global burden of disease study 2013. Lancet. 2014;384(9945):766-81.

3. Institute of Public Health Malaysia. National Health and Morbidity Survey 2011. Non communicable diseases. Volume II. Institute of Public Health Malaysia. 2011. 192 p. Available from: http://www.iku.gov.my/ images/IKU/AQ9Document/REPORT/NHMS2011-Volumell.pdf. Accessed 21 Nov 2013.

4. Institute of Public Health Malaysia. National Health \& Morbidity Survey 2015. Non-communicable diseases, risk factors \& other health problems. [Internet]. Kuala Lumpur: Institute of Public Health Malaysia; 2015. Available from: http://www.iku.gov.my/images/IKU/Document/REPORT/ nhmsreport2015vol2.pdf. Accessed 20 Apr 2016.

5. World Health Organization. Obesity and overweight [Internet]. Geneva: World Health Organization; 2018. Available from: http://www.who.int/ news-room/fact-sheets/detail/obesity-and-overweight. Accessed 20 July 2018.

6. Department of Statistics Malaysia. Current population estimates, Malaysia, 2014-2016. 2017. Available from: https://www.dosm.gov.my/v1/index. php?r=column/cthemeByCat\&cat=155\&bul_id= OWIxdEVoYIJCSOhUZZJyRUcvZEYXZZ09\&menu idLOpheU43NWJwRWVSZkIWdzQ4TIhUUT09. Accessed 4 Jan 2016.

7. Mudd-martin G, Martinez MC, Rayens MK, Meininger JC. Sociocultural tailoring of a healthy lifestyle intervention to reduce cardiovascular disease and type 2 diabetes risk among Latinos. Prev Chronic Dis. 2013; 10(E200):1-10

8. Epstein LH. Family-based behavioural intervention for obese children. Int J Obes Relat Metab Disord. 1996;20(Suppl 1):S14-21.

9. Epstein LH, Valoski A, Wing RR, McCurley J. Ten-year outcomes of behavioral family-based treatment for childhood obesity. Health Psychol. 1994;13(5):373-83.
10. Gruber KJ, Haldeman LA. Using the family to combat childhood and adult obesity. Prev Chronic Dis. 2009;6(3):A106.

11. Moens $E$, Braet $C$. Training parents of overweight children in parenting skills: a 12-month evaluation. Behav Cogn Psychother. 2012;40(01):1-18.

12. Epstein LH, Paluch RA, Roemmich JN, Beecher MD. Family-based obesity treatment, then and now: twenty-five years of pediatric obesity treatment. Health Psychol. 2007;26(4):381-91.

13. Institute of Medicine. Parents can play a role in preventing childhood obesity. Fact sheet. 2004. Available from http://www.nationalacademies. org/hmd/ /media/Files/Report\%20Files/2004/Preventing-ChildhoodObesity-Health-in-the-Balance/FactSheetHomeFINALBitticks.ashx. Accessed 31 May 2018.

14. Coppock JH, Ridolfi DR, Hayes JF, St. Paul M, Wiffley DE. Current approaches to the Management of Pediatric Overweight and Obesity. Curr Treat Options Cardiovasc Med. 2014;16(11):1-15.

15. Lindsay AC, Sussner KM, Kim JGS. The role of parents in preventing childhood obesity. Futur Child. 2006;16(1):169-86.

16. Jiang JX, Xia XL, Greiner T, Lian GL, Rosenqvist U. A two year family based behaviour treatment for obese children. Arch Dis Child. 2005; 90(12):1235-8.

17. McGarvey E, Keller A, Forrester M, Williams E, Seward D, Suttle DE. Feasibility and benefits of a parent-focused preschool child obesity intervention. Am J Public Health. 2004:94(9):1490-5.

18. Golley RK, Perry RA, Magarey A, Daniels L. Family-focused weight management program for five- to nine-year-olds incorporating parenting skills training with healthy lifestyle information to support behaviour modification. Nutr Diet. 2007;64(3):144-50.

19. Marshall S, Golley R, Hendrie G. Expanding the understanding of how parenting influences the dietary intake and weight status of children: a cross-sectional study. Nutr Diet. 2011;68(2):127-33.

20. Skelton JA, Beech BM. Attrition in paediatric weight management: a review of the literature and new directions. Obes Rev. 2011;12(5):e273-81.

21. Statista. Most popular social networks worldwide as of April 2018, ranked by number of active users (in millions). 2018. Available from: https://www. statista.com/statistics/272014/global-social-networks-ranked-by-number-ofusers/. Accessed 31 May 2018.

22. Malaysian Communications and Multimedia Commission. Internet users survey 2017. 2017 Available from: https://www.mcmc.gov.my/skmmgovmy/ AQ16media/General/pdf/MCMC-Internet-Users-Survey-2017.pdf. Accessed 24 May 2018.

23. Maher C, Ryan J, Kernot J, Podsiadly J, Keenihan S. Social media and applications to health behavior. Curr Opin Psychol. 2016;9:50-5. Available from: https://doi.org/10.1016/j.copsyc.2015.10.021

24. Laranjo L, Arguel A, Neves AL, Gallagher AM, Kaplan R, Mortimer N, et al. The influence of social networking sites on health behavior change: a systematic review and meta-analysis. J Am Med Inform Assoc. 2015; 22(1):243-56

25. Dahl AA, Hales SB, Turner-McGrievy GM. Integrating social media into weight loss interventions. Curr Opin Psychol. 2016;9:11-5.

26. Herring SJ, Cruice JF, Bennett GG, Davey A, Foster GD. Using technology to promote postpartum weight loss in urban, low-income mothers: a pilot randomized controlled trial. J Nutr Educ Behav. 2014;46(6):610-5.

27. Napolitano M, Hayes S, Bennett G, Ives AK, Foster GD. Using Facebook and text messaging to deliver a weight loss program to college students. Obes J. 2013;21(1):25-31.

28. Patrick K, Marshall SJ, Davila EP, Kolodziejczyk JK, Fowler JH, Calfas KJ, et al. Design and implementation of a randomized controlled social and mobile weight loss trial for young adults (project SMART). Contemp Clin Trials. 2014;37(1):10-8.

29. Doub AE, Small M, Birch LL. A call for research exploring social media in $\mathrm{fl}$ uences on mothers ' child feeding practices and childhood obesity risk. Appetite. 2016;99:298-305.

30. Norliza A, Lye MS, Zalilah MS, Firdaus M. Harnessing social media in family-based intervention for childhood obesity: Study protocol fro randomised controlled field trial of REDUCE programme. 2016;3(5):95109. Available from: http://publichealthmy.org/ejournal/ojs2/AQ17index. php/ijphcs/article/view/341.

31. Urbaniak GC, Plous S. Research randomizer [Internet]. 2007. 2007. Available from: https://www.randomizer.org/. Accessed 11 Feb 2015.

32. Sacher PM, Kolotourou M, Chadwick PM, Cole TJ, Lawson MS, Lucas A, et al. Randomized controlled trial of the MEND program: a family-based 
community intervention for childhood obesity. Obesity (Silver Spring). 2010; 18(Suppl 1):S62-8.

33. Bandura A. Social foundations of thought and action: a social-cognitive theory. Prentice-hall. Englewood Cliffs, NJ: Prentice-Hall; 1986.

34. World Health Organization. WHO Anthroplus [Internet]. 2006. Available from: http://en.freedownloadmanager.org/Windows-PC/WHO-AnthroPlus-FREE. html. Accessed 6 Mar 2015.

35. World Health Organization. Waist Circumference and Waist-Hip Ratio: Report of a WHO Expert Consultation. Geneva: World Heal Organ; 2008. (December):8-11.

36. Poh BK, Nurul Jannah A, Chong LK, Ruzita AT, Mohd Noor I, McCarthy D. Waist circumference percentile curves for Malaysian children and adolescents aged 6.0 - 16.9 years. Int J Pediatr Obes. 2011;6(3-4):229-35.

37. Waters E, de Silva-Sanigorski A, Hall BJ, Brown T, Campbell K, Gao Y, et al. Interventions for preventing obesity in children. Cochrane Database Syst Rev. 2011;(12):CD001871.

38. Kolsgaard MLP, Joner G, Brunborg C, Anderssen SA, Tonstad S, Andersen LF. Reduction in BMI z-score and improvement in cardiometabolic risk factors in obese children and adolescents. The Oslo adiposity intervention study a hospital/public health nurse combined treatment. BMC PediatrBioMed Central Ltd. 2011;11(1):47.

39. Hammersley M, Jones R, Okely A. Parent-Focused Childhood and Adolescent overweight and obesity eHealth interventions: a systematic review and meta-analysis [internet]. J Med Internet Res. 2016;18(7).

40. Wilfley DE, Stein Rl, Saelens BE, Matt GE, Hayden-wade HA, Welch RR, et al. Efficacy of Maintenance Treatment J Am Med Assoc. 2007:298(14):1661-73.

41. Croker H, Viner R, Nicholls D. Family-based Behavioural treatment of childhood obesity in a UK National Health Service setting : randomised controlled trial. J Obes. 2011;36(1):1-19.

42. McCallum Z, Wake M, Gerner B, Baur LA, Gibbons K, Gold L, et al. Outcome data from the LEAP (live, eat and play) trial: a randomized controlled trial of a primary care intervention for childhood overweight/mild obesity. Int J Obes. 2007;31(4):630-6

43. Hughes AR, Stewart L, Chapple J, McColl JH, Donaldson MDC, Kelnar $\mathrm{CJH}$, et al. Randomized, controlled trial of a best-practice individualized behavioral program for treatment of childhood overweight: Scottish childhood overweight treatment trial (SCOTT) Pediatrics. 2008;121(3):e539-46.

44. Boudreau ADA, Kurowski DS, Gonzalez WI, Dimond MA, Oreskovic NM Latino families, primary care, and childhood obesity: A randomized controlled trial. Am J Prev Med. 2013;44(3 Suppl 3):S247-57.

45. Kalavainen M, Korppi M, Nuutinen O. Long-term efficacy of group-based treatment for childhood obesity compared with routinely given individual counselling. Int J Obes Nature Publishing Group. 2011;35(4):530-3.

46. Reinehr T, Schaefer A, Winkel K, Finne E, Toschke AM, Kolip P. An effective lifestyle intervention in overweight children: findings from a randomized controlled trial on ' Obeldicks light. Clin Nutr. 2010;29(3):331-6.

47. Chen JL, Weiss S, Heyman MB, Cooper B, Lustig RH. The efficacy of the web-based childhood obesity prevention program in Chinese American adolescents (web ABC study). J Adolesc Health. 2011:49(2):148-54.

48. Yamashita K, Kondo T, Osugi S, Shimokata K, Maeda K, Okumura N, et al. The significance of measuring body fat percentage determined by bioelectrical impedance analysis for detecting subjects with cardiovascular disease risk factors. Circ J. 2012;76(10):2435-42.

49. Derek Cheung YT, Helen Chan CH, Lai CK, Vivian Chan WF, Wang MP, William Li HC, et al. Using Whatsapp and Facebook online social groups for smoking relapse prevention for recent quitters: a pilot pragmatic cluster randomized controlled trial. J Med Internet Res. 2015;17(10):1-15.

50. Lingaraju VS. Why are people choosing WhatsApp Messenger over Facebook Messenger? [Internet]. 2013 [cited 2017 Jan 3]. Available from: https://www.quora.com/Why-are-people-choosing-WhatsApp-Messengerover-Facebook-Messenger. Accessed 3 Jan 2017.

51. Amrita K. The pros and cons of Facebook Messenger and WhatsApp [Internet]. The Daily Dot. 2017 [cited 2018 May 31]. Available from: https:/ www.dailydot.com/debug/facebook-messenger-vs-whatsapp/. Accessed 31 May 2018.

\section{Ready to submit your research? Choose BMC and benefit from:}

- fast, convenient online submission

- thorough peer review by experienced researchers in your field

- rapid publication on acceptance

- support for research data, including large and complex data types

- gold Open Access which fosters wider collaboration and increased citations

- maximum visibility for your research: over $100 \mathrm{M}$ website views per year

At BMC, research is always in progress.

Learn more biomedcentral.com/submissions 